\title{
Educação permanente em saúde e desenvolvimento adulto: a experiência das oficinas fotográficas de sensibilização do olhar
}

\section{Permanent health education and adult development: an experience based on the Eye's Sensitization Photography Workshop}

\section{Caroline Zamboni de Souza', Leandro Artur Anton², Maria Claudia Santos Lopes de Oliveira ${ }^{3}$}

\begin{abstract}
Resumo
Este artigo apresenta e analisa uma iniciativa de formação no trabalho desenvolvida como parte da produção de um livro sobre experiências de Educação Permanente em Saúde (EPS) do Sistema Único de Saúde, na qual os dois primeiros autores atuaram com equipe de facilitadores. A Oficina Fotográfica de Sensibilização do Olhar foi realizada em três diferentes localidades brasileiras. A oficina utilizou como principal recurso metodológico artefatos fotográficos rudimentares e, como método, os percursos fotográficos no território de atuação dos profissionais. A produção de narrativas imagéticas também contou com vivências de sensibilização de outros sentidos além da visão - como a vivência do silêncio e do uso das habilidades táteis. A produção de narrativas sobre o trabalho em saúde tornou possível o estranhamento do cotidiano laboral favorecendo, desse modo, o desenvolvimento humano dos participantes e o reconhecimento do valor das estratégias de EPS que partem da realidade de cada Lugar.
\end{abstract}

Palavras-chave: Fotografia. Educação Permanente em Saúde. Desenvolvimento humano. Geografia. Territorialidade.

\begin{abstract}
This paper presents and analyses an initiative of training at work developed as part of the production of a book on experiences in Permanent Health Education (EPS) of the Brazilian Unified Health System (SUS), in which the first two authors worked with a team of facilitators. The Eye's Sensitization Photography Workshop was conducted in three different Brazilian locations. The workshop used as its main methodological resource rudimentary photographic devices and, as the method, photographic walkings in the working territory of the professionals. The production of visual narratives also counted on experiences of sensitization of other senses beyond sight - such as the experience of silence and the use of tactile skills. The production of narratives about health work leaded to the estrangement of the everyday life in workplace, thus favouring participants' human development, and the recognition of the value of EPS strategies that consider the local reality.
\end{abstract}

Keywords: Photography. Permanent Health Education. Human development. Geography. Territoriality.

\footnotetext{
${ }^{1}$ Universidade de Brasília, Brasília, DF, Brasil. E-mail: carolinezambonidesouza@gmail.com

2 Ponto de Cultura Quilombo do Sopapo, Porto Alegre, RS, Brasil. E-mail: lantonarq@gmail.com

${ }^{3}$ Universidade de Brasília, Brasília, DF, Brasil. E-mail: mcsloliveira@gmail.com
} 


\section{Introdução}

Nos últimos anos, o uso crescente de tecnologias da informação, a complexificação das práticas laborais e as exigências próprias do mercado de trabalho capitalista, têm levado à ampliação de processos educacionais para além da escola regular e à necessidade de formação ao longo da vida, aspectos que conferem mais importância ao debate educacional ligado à formação de adultos. Ao mesmo tempo, o cenário contemporâneo coloca a necessidade de problematizar a produção de conhecimento e sua relação com o mundo do trabalho, prevenindo que a formação se converta em atividade mecânica orientada sobretudo por interesses extrínsecos ao trabalhador.

Este artigo refere-se a um relato de experiência, no qual analisaremos uma prática educacional inovadora, realizada com trabalhadores do SUS, chamada "Oficina Sensibilização do Olhar"'. Tais oficinas ocorreram em meio a ações de Educação Permanente em Saúde, realizadas em todo o Brasil, e as que serão aqui relatadas se deram em três contextos de distintas regiões, a saber: o agreste pernambucano, o planalto meridional catarinense e a Floresta Amazônica.

A Oficina Sensibilização do Olhar teve como objetivo envolver os trabalhadores na composição de um livro ${ }^{4}$ que retrata projetos de Educação Permanente em Saúde (EPS), no âmbito do SUS. Nosso foco, ao apresentar este

\footnotetext{
${ }^{4}$ O InovaSUS 2015 - Gestão da Educação na Saúde foi uma ação de reconhecimento e cooperação ligada à Política Nacional de Educação Permanente em Saúde. Uma parceria entre Ministério da Saúde e Organização Pan-Americana de Saúde que selecionou 38 projetos de todas as regiões do país para receberem
}

relato, volta-se para a oportunidade de desenvolvimento humano adulto e Educação Permanente em Saúde possibilitada pela oficina, dada a utilização de dispositivos pedagógicos relacionados à produção de fotografias com artefatos rudimentares.

Iniciaremos por apresentar os elementos teórico-conceituais norteadores da análise da experiência, relacionados aos temas: (i) Educação Permanente em Saúde; e (ii) desenvolvimento adulto. Em seguida, faremos uma apresentação introdutória sobre fotografia como dispositivo para a produção de narrativas de trabalhadores da saúde utilizando câmeras rudimentares; ao final, descreveremos e analisaremos a experiência das oficinas, propriamente dita.

\section{Educação Permanente em Saúde}

A Educação Permanente em Saúde (EPS) caracteriza-se por ser uma prática de produção e compartilhamento de conhecimento vinculado ao cotidiano do trabalho. A EPS constitui-se a partir de problematizações e processos significativos. Busca, além do desenvolvimento de saberes técnicos, a produção de um imbricamento entre ações laborais e dimensões ético-políticas do trabalho. Nesse sentido, é uma proposta político-pedagógica para viabilizar processos de educação que visam promover a integralidade, a humanização e a cidadania de todos os atores envolvidos no Sistema Único de Saúde (SUS), conforme Ceccim

recurso para viabilizar suas propostas. Foi construído um livro de fotografia para apoiar a divulgação e a ampliação das redes territoriais dos projetos. O livro pode ser visto em http://www.youblisher.com/p/1703471-LivroInovaSUS-2015-Gestao-da-Educacao-na-Saude/ 
e Ferla (2009). Além de uma prática políticopedagógica, a EPS também é uma política de educação em saúde, com a qual se objetiva contribuir com a consolidação e fortalecimento do SUS, por meio da formação e desenvolvimento de trabalhadores. Como Política Nacional do SUS, já contou com duas versões: a primeira, datada de 2004, e a segunda, de 2007 (Ministério da Saúde, 2004; Ministério da Saúde, 2007).

Para Merhy (2013), o princípio pedagógico básico da EPS refere-se à necessidade de reconhecer que a produção de saberes no cotidiano de trabalho é contínua e "não pede licença" para acontecer. Portanto, torna-se um desafio para todos os atores do Sistema Único de Saúde identificar e reconhecer essas práticas que se dão no encontro com o outro, produzindo sentido ético e político para o seu fazer no campo da saúde. Abrir um movimento que procure reconhecer esses acontecimentos, torná-los visíveis, pode ser uma boa aposta para mudar o eixo dos processos de formação e capacitação no campo da saúde (p. 2).

Desse modo, a EPS pode acontecer tanto em momentos cotidianos e rotineiros do trabalho, tais como o encontro para um cafezinho (em que se forje a oportunidade para a análise e o debate de um caso que intrigue um profissional, por exemplo), quanto em momentos mais formais e estruturados (como uma reunião de equipe na qual se estude questões que emerjam dos encontros vividos por trabalhadores, usuários e estagiários de um serviço, por exemplo). Apesar de relevante, o reconhecimento dessas práticas e a construção de estratégias de colaboração que ampliem o impacto desses encontros, na perspectiva de "contribuir para dar visibilidade e dizibilidade ao movimento de educação permanente que já existe, nos lugares", ainda é um desafio (Merhy, 2013, p. 4).

A EPS acontece a partir da ativação de um movimento de desacomodação, ou seja, é preciso haver um certo "estranhamento" do trabalhador em saúde sobre aquilo que parece comum, natural, corriqueiro, do qual possa emergir um novo olhar sobre a prática. Nesse sentido, a construção de dispositivos que possibilitam colocar o trabalho em análise, tal como propôs a Oficina Sensibilização do Olhar que será apresentada adiante, pode contribuir para gerar tal estranhamento. "Não se trata de conhecer mais e de maneira mais crítica e consciente, trata-se de mudar" (Ceccim \& Ferla, 2009, para. 10), de inventar novas formas de olhar e praticar o trabalho em saúde.

Os mesmos autores (Ceccim \& Ferla, 2009) apontam que para desnaturalizar o vivido é fundamental a construção de espaços democráticos onde diferentes pontos de vista possam emergir como questionamento do cotidiano e possibilidade de invenção de novas formas de produzir saúde, levando às aprendizagens e à transformação das equipes de trabalho em coletivos organizados de desenvolvimento, com ganhos subjetivos, coletivos e para o próprio serviço. À medida que a interação afetiva e democrática passe a caracterizar as práticas dos profissionais da saúde a cada encontro, seja com o usuário, seja com colegas de trabalho, gestor ou instituições formadoras e destes com os territórios da saúde, a construção de fissuras e possibilidades de inovação são potencializadas. Assim as concepções rígidas e monolíticas de educação e realidade podem ser desnaturalizadas. 
Nessa direção, os processos de EPS precisam gerar em cada trabalhador oportunidades para a problematização de si mesmo e do seu agir, a ponto que mobilizem a prática profissional para produção de integralidade na atenção em saúde (Merhy, 2005). De acordo com esse autor, esses são os maiores desafios da educação permanente: "produzir autointerrogação de si mesmo no agir produtor do cuidado; colocar-se ético-politicamente em discussão, no plano individual e coletivo, do trabalho" (p. 173). Há a necessidade de se produzir analisadores que toquem "a alma do operar ético-político do trabalhador e dos coletivos na construção do cuidado, que é o modo como estes dispõem do seu trabalho vivo em ato, enquanto força produtiva do agir em saúde". Em busca de encarar o desafio de produzir dispositivos que possam "tocar" os trabalhadores e seus coletivos nas suas singularidades e relações, propomos um diálogo com um referencial de Psicologia do desenvolvimento humano adulto que contribua na identificação desses dispositivos potentes para construção de processos de autointerrogação de si.

\section{Desenvolvimento adulto}

O desenvolvimento profissional é um aspecto bastante relevante na vida de um adulto da espécie humana. O trabalho é uma atividade relacionada à sobrevivência, sem a qual os sujeitos, sobretudo no modo de organização social capitalista, estão privados de obter o sustento de suas necessidades básicas. Porém, o trabalho não se restringe à sobrevivência, configurando-se, também, como um instrumento de constituição de si, da sociedade e da cultura essa última característica tensiona todo o arranjo do modo de produção. A lógica de assalariamento do trabalhador, no sistema capitalista, compromete significativamente a vivência da expressão autocriadora do trabalho.

Para Merhy (2006), entretanto, os setores de saúde e educação, por exemplo, constituem exceções a essa regra, pois caracterizam-se por uma potência que não sucumbe completamente ao capitalismo. Nesse tipo de prática laboral, existiria sempre a possibilidade de uma brecha, que seria produzida pela necessidade de um encontro genuíno com o outro a fim de que a produção laboral se efetive. Em outras palavras, o fruto do trabalho nesses setores é sempre definido como uma cocriação; o trabalhador está sempre sendo convocado a criar com seus pares e a reconhecer novos saberes que possibilitem inventar trajetórias de desenvolvimento significativas para si e para o coletivo.

Para Lopes de Oliveira e Souza (2019), as contribuições da Psicologia do desenvolvimento ainda são bastante contraditórias no campo da educação e do desenvolvimento profissional. Existem uma série de teorias clássicas, amplamente divulgadas, que trabalham com modelos de desenvolvimento humano e aprendizagem normativos e prescritivos, fundamentados no conceito de estágios ou fases universais que se concluem na adolescência. Nelas a adultez é apresentada como um longo intervalo no qual o desenvolvimento humano está concluído e a interrogação sobre si faz pouco sentido, uma vez que o sujeito está pronto, acabado, maduro, sem lugar para mais mudanças qualitativas na estrutura psíquica da pessoa. Tais abordagens têm limites explicativos importantes 
e contribuem com uma visão equivocada da adultez, supostamente marcada por equilíbrio e fixidez. De acordo com essa via, a vida adulta opõe-se às fases precedentes, caracterizadas pelas céleres transformações biológicas da infância e da adolescência, e consequentes, as transformações e possíveis degenerações impostas pelo envelhecimento.

Como em todo o curso de vida, o desenvolvimento adulto decorre da dinâmica entre continuidade e descontinuidade do sentido de si e das relações estabelecidas, que variam de acordo com o momento histórico e a sociedade de qual se faz parte. Destacamos, entre as relações culturalmente típicas da condição adulta ocidental, as relações socioafetivas e amorosas; as etapas significativas da formação educacional e aprendizagens sociais diversas e os contextos de trabalho. Tal como vimos argumentando nas linhas anteriores, a EPS tem aspectos relacionais, laborais e formativos que podem contribuir com a ampliação de saberes no campo da Psicologia do desenvolvimento adulto.

As narrativas têm se apresentado como um importante dispositivo na pesquisa dos processos de desenvolvimento humano (Almeida \& Valente, 2012; Bamberg, 1996, 2004; Lopes de Oliveira, 2006, 2012), e também possibilita compreender o desenvolvimento adulto no trabalho, como mostram os estudos de Luiz, Mello, Ventorim, Ferreira Neto e Santos (2016), Rodrigues e Gonçalves (2014). No trabalho desses autores, são priorizadas as análises de narrativas verbais, em situação de conversações espontâneas, contação de histórias, entrevista

\footnotetext{
${ }^{5}$ Vide a experiência da plataforma Comunidade de Práticas e a IV Mostra Nacional de Atenção Básica. Para saber mais sobre a Comunidade de Práticas acesse https://novo.atencaobasica.org.br/mostra. Para
}

individual, grupal e oficinas temáticas, entre outros. Já autores como Possamai (2007), Reznik e Araújo (2007), Paleari e Biz (2010) propõem a abordagem de narrativas visuais. Anton (2015) diz que a fotografia, pela autonomia e pela possibilidade de uso e relação cotidiana, produz mais do que registros, são a trajetória e o percurso de vida de quem está produzindo as fotografias, ou seja, a fotografia é um potente dispositivo para a produção de narrativas visuais.

As narrativas verbais - orais e escritas -, assim como as visuais, são uma ferramenta importante no trabalho em EPS, contribuindo para ampliação das possibilidades de comunicação e reconhecimento de práticas de educação permanente no SUS. $^{5}$ A natureza colaborativa e compartilhada do trabalho no âmbito da saúde faz com que o trabalhador se beneficie amplamente da comunicação de registros pessoais e coletivos que coloquem em análise experiências vivenciadas e trajetórias seguidas pelos trabalhadores do SUS para produção de conhecimento no trabalho e inspiração de novas práticas.

Neste artigo, relatamos uma experiência particular de três grupos participantes de uma ação de EPS, que consistiu em construir narrativas fotográficas sobre $\mathrm{o}$ trabalho de profissionais da saúde, no cenário da atividade denominada "Oficina Sensibilização do Olhar". A peculiaridade da experiência aqui relatada é a realização de percursos fotográficos com o uso de câmeras rudimentares e outros artefatos. A orientação para a construção de uma narrativa fotográfica a partir dos recursos técnicos

detalhes da IV Mostra Nacional de Atenção Básica, consulte http://dab.saude.gov.br/portaldab/noticias.php?cont eudo=_\&cod=1798. 
primitivos disponíveis permitiu que os participantes superassem obstáculos e exercitassem o reconhecimento de aspectos de desenvolvimento pessoal integrado a um projeto coletivo. Entre outros efeitos, os dispositivos utilizados provocaram estranhamentos em relação ao cotidiano de trabalho e levaram a formas de interação afetiva mais empática com os colegas e com os lugares onde vivem e atuam. Percebeu-se que a produção da narrativa fotográfica mobilizou a experimentação da criatividade no âmbito mental, afetivo, corporal e relacional no contexto de trabalho, sensibilizando os trabalhadores para o cultivo de práticas de Educação Permanente em Saúde.

\section{A fotografia como dispositivo para promover narrativas de trajetórias de desenvolvimento adulto e Educação Permanente em Saúde}

Dispositivo é um "artifício produtor de inovação" que promove "realidades alternativas e revolucionárias que transformam o horizonte considerado do real" (Baremblitt, 2002, p. 135). Um dispositivo é algo capaz de gerar um acontecimento que pode tanto explicitar conflitos como promover diálogos. São recursos de ordem artística, política, comunicacional, estatística, ou outro, que: (i) contribuam para constituição de uma ação que (ii) promova o engajamento de um grupo em torno de algo que vai ser colocado em questão, (iii) "produzindo assim um artefato próximo à vida cotidiana", mas que, ao mesmo tempo, (iv) possibilita seu estranhamento (Baremblitt, 2002, p. 135). Nessa experiência que está sendo relatada, foram propostos como dispositivos distintos recursos e ações em torno do uso de câmeras fotográficas rudimentares e percursos fotográficos, no caso, para produzir narrativas visuais acerca da prática profissional em saúde.

O uso de fotografias como dispositivo de processos educacionais não é algo inovador, mas amplamente utilizado devido ao seu potencial para disparar a imaginação e, daí em diante, esquemas cognitivos, afetivos e estéticos de crescente complexidade, relacionados às funções psicológicas superiores. Entre os potenciais da utilização da fotografia, ademais, está a sua eficiência na ativação e narração de memórias, produção de significados e desenvolvimento da atenção do observador em relação a lugares, pessoas e gestos (Anton, 2015). Atualmente a fotografia ganhou novos espaços, popularizou-se e faz parte da vida da maioria das pessoas. Sua versão digital, disseminada especialmente devido aos recursos disponíveis nos aparelhos de telefonia celular, objetos de uso pessoal e cotidiano, permite ao portador a utilização desse recurso em qualquer percurso que realize. A ampliação da presença da fotografia na vida cotidiana, por um lado, pode banalizá-la numa mera produção de imagens em grande quantidade, mas por outro é um sinal de sua democratização, transformando-a em instrumento de facilitação da comunicação e de construção de memória social dos lugares e dos fazeres cotidianos.

Sontag (1981, p. 4) define que "fotografar é apropriarmo-nos da coisa fotografada. Significa envolvermo-nos numa certa relação com o mundo que se assemelha ao conhecimento e, por isso, ao poder." Dessa forma, a fotografia não é apenas uma forma de representação da realidade, mas também pode ser uma forma de criação de realidades possíveis. A 
autora afirma que a fotografia pode transformar os lugares, na medida em que tem o poder de criar recortes, aproximações e distanciamentos, ampliando e explicitando detalhes que tendem a ser pouco percebidos no cotidiano (Sontag, 2004). A partir dessa perspectiva, consideramos que a fotografia constitui um dispositivo pedagógico para produção de processos de desenvolvimento humano e educação permanente, pois coerentemente com os princípios da EPS, possibilita a criação de narrativas que ativam o estranhamento do sujeito em relação ao cotidiano e não apenas a captura deste em imagem.

Fotografar é uma ação de conceder relevância a algo que afetou o fotógrafo (Sontag, 1981), e o ato de compartilhar essas relevâncias contribui para a produção de novos significados, o que justifica a utilização da fotografia como recurso pedagógico. "A fotografia é uma porção pequena do espaço, bem como do tempo" (Sontag, 1981, p. 22). Com o fim de "desnaturalizar" o ato de fotografar, explicitar os atributos da fotografia na construção de estranhamentos do cotidiano e ressaltar sua face produtora de democratização, optamos pela utilização na Oficina Sensibilização do Olhar, ${ }^{6}$ de outros artefatos fotográficos, além dos celulares, que poderiam ser construídos pelos próprios participantes. Os artefatos rudimentares produzidos possibilitaram acentuar a experiência

\footnotetext{
${ }^{6}$ A construção da oficina Sensibilização do Olhar tem sua metodologia inspirada em duas experiências precedentes do segundo autor (Anton, 2007, 2010), a primeira realizada como parte do projeto de extensão universitária da UFRGS chamado Conexão de Saberes, com o nome Qual é a Lata do Lugar? E, a segunda, realizada pela equipe do Ponto de Cultura Quilombo do Sopapo na Residência Artística Interações Estéticas Imagens Faladas, que gerou $\mathrm{O}$ livro
}

sensorial e cognitiva, em várias dimensões: da observação sensível; da vivência de uma modulação lenta do tempo; da experimentação de uma estética incomum, similar à onírica; da ativação de memórias, afetos e reconstruções criativas do cotidiano.

\section{O método do percurso fotográfico}

Um recurso amplamente utilizado nas oficinas foi a vivência de percursos, um método de produção fotográfica que parte da ativação e da sensibilização do olhar a partir do ato de caminhar, individual ou em grupo, por nichos de um certo lugar sobre o qual se quer produzir registros e/ou novos olhares. De acordo com os objetivos formativos das oficinas, o percurso fotográfico possibilitou a construção de narrativas sobre o cotidiano profissional.

A ideia de percurso remete à noção de lugar e território como uma dimensão fundamental para se pensar o cotidiano do profissional de saúde. Para Relph (2012, p. 6), "lugar é onde conflui a experiência cotidiana, e também como essa experiência se abre para o mundo." O percurso, como prática cotidiana, é gerador do encontro com o outro e também com o território. Pela rotina, esse exercício (o ato de caminhar), é comumente feito no dia a dia com o objetivo de chegar a um destino o mais rápido possível, abrindo mão da observação atenta do

http:/ /www.youblisher.com/p/76241-ImagensFaladas-Livro-do-Cristal/ e um minidocumentário: Imagens Faladas - reportagens fotográficas sobre a memória do Bairro Cristal https://www.youtube.com/watch?v=BxsxXwkK1 kw \&list=PLV-z6pH6Q5EJ2vgBPmxoIMpFsdqOzva--. Ambas as experiências aconteceram em Porto Alegre e tiveram como participantes estudantes de escolas públicas e jovens da comunidade local. 
trajeto percorrido e, consequentemente, da captação de informações que têm potencial para mobilizar os processos de EPS. Esse deslocamento apressado pode não permitir que o trabalhador da saúde perceba o caminho. Para Relph (2012, p. 29), o percurso também é parte Lugar, "que é uma reunião e uma abertura do ser com potencial para a continuidade, mas é constantemente desafiado pelas tecnologias e formas de pensamento que desejam diminuí-lo. A experiência de lugar precisa estar continuamente lutando para ser renovada e reforçada."

Portanto, o percurso na Oficina Sensibilização do Olhar é uma prática de estudo do território da saúde como Lugar, que "tem um papel importante a desempenhar para compreender e, talvez, corrigir a insistência neoliberal na eficiência global de ganhos que diminui a qualidade de nossas vidas, erodindo tudo que é local. Em suma, estudar e promover lugar [...] é uma prática de resistência" (Relph 2012, p. 5).

A organização do SUS está atrelada a uma organização espacial e populacional por meio da regionalização e da adscrição. A dimensão territorial é central no processo de consolidação do SUS e torna-se ainda mais relevante quando falamos de experiências que tratam da atenção básica e do fortalecimento de redes de cuidado, tais como os projetos de Educação Permanente em Saúde que participaram das oficinas.

O percurso fotográfico é um exercício de promoção de novos olhares sobre o cotidiano a partir do reconhecimento daquilo que afeta, mobiliza ou desacomoda, no caso, instigado pelos artefatos fotográficos propostos. De acordo com Certeau (1998, p. 177), "o ato de caminhar [...] é uma realização espacial do lugar, assim como o ato de palavra é uma realização sonora da língua... o ato de caminhar parece, portanto, encontrar uma primeira definição como espaço de enunciação". É uma convocação ao registro de um estranhamento daquilo que é corriqueiro. Nesse sentido, o método proposto converge com proposta da EPS, ao provocar uma atualização das trajetórias pessoais e coletivas e possibilitar novas percepções e processos de desenvolvimento humano.

A Oficina Sensibilização do Olhar, por se relacionar com o cotidiano dos trabalhadores nos seus espaços de prática e troca de saberes a partir do uso de dispositivos da fotografia, utilizou o conceito de Lugar, caro à Geografia, para constituição da proposta dos percursos fotográficos. Historicamente, o Lugar como espaço geográfico na cultura capitalista é o que menos tem influenciado nas tomadas de decisão dos processos de mudanças sociais, visto que é solapado pela produção capitalista da especulação imobiliária, da apropriação pelo turismo de consumo, pela gentrificação etc. Experiências que promovam a sensibilidade ao Lugar favorecem a elaboração e comunicação de narrativas que ultrapassam as fronteiras locais e permitem processos mais robustos de resistência, sobre seus rumos e transformações na forma de processos vivos, reais e participativos. Milton Santos ressalta o papel do Lugar nos processos de resistência e transformação social:

Por enquanto, o Lugar - não importa sua dimensão - é, espontaneamente, a sede da resistência, às vezes involuntária, da sociedade civil, mas é possível pensar em elevar esse movimento a desígnios mais 
amplos e escalas mais altas. Para isso é indispensável insistir na necessidade de um conhecimento sistemático da realidade, mediante o tratamento analítico do território, interrogando-o a propósito de sua própria constituição no momento histórico atual. (Santos, 2004, p. 259)

O Lugar está ligado ao cotidiano, à autonomia, a afetividade, à identidade e ao encontro, é nele que se dão os processos de desenvolvimento humano e Educação Permanente em Saúde. Por fim, o Lugar é onde se que constroem "novas horizontalidades que permitirão, a partir da base da sociedade territorial, encontrar um caminho que se anteponha à globalização perversa e nos aproxime da possibilidade de construir uma outra globalização" (Santos, 2004, p. 259).

A Oficina Sensibilização do Olhar, a partir da referência ao conceito de Lugar para promover o encontro nos territórios da saúde, nos indicava adaptabilidade e compatibilidade para lidar com a diversidade geográfica, distintas formações profissionais e também com a diversidade de serviços e instituições que compõem o SUS. Os territórios vivenciados foram (i) o agreste, transição da mata atlântica para caatinga, do litoral para o sertão: o encontro se deu a partir da universidade pública em um curso de Medicina que implementa as novas diretrizes curriculares envolvendo professores, funcionários, estudantes, trabalhadores dos serviços, artistas da cidade e usuários dos serviços de saúde; (ii) o planalto meridional catarinense com mata de araucárias, baixíssimas temperaturas e, ao mesmo tempo, variações climáticas acentuadas: o encontro foi marcado pela presença majoritária de mulheres trabalhadoras da saúde, atuantes na redução da mortalidade infantil, a partir da Rede Cegonha; (iii) a Floresta Amazônica, o encontro se deu majoritariamente com homens, Agentes Comunitários De Saúde E Microscopistas membros das comunidades ribeirinhas e aldeias indígenas, onde o tempo dos deslocamentos no território é marcado pelo fluxo das águas e pelos agravos típicos do território amazonense, um bioma transfronteiriço.

\section{Artefatos fotográficos rudimentares}

As câmeras fotográficas rudimentares caracterizam-se por não terem lentes e podem ser produzidas a partir de diferentes materiais e modos de funcionamento. As que foram utilizadas nas oficinas são as câmeras pinhole.

O pinholoscópio é um artefato que possibilita visualizar a projeção fotográfica que acontece dentro de uma câmera. São construídos dois prismas quadrangulares retos com papel cartão com uma face preta, com pequena diferença de tamanho para permitir que um entre dentro do outro. O prisma menor tem uma de suas extremidades cobertas com papel vegetal, que funciona como tela para a projeção da imagem, e no maior uma das extremidades é vedada com papel-alumínio. Com a ponta de uma agulha é feito um pequeno orifício neste último para permitir a entrada da luz e a formação de imagem no papel vegetal, visualizada pela extremidade oposta, aberta. Como esse artefato não permite o registro da imagem, apenas sua visualização, telefones celulares foram utilizados simultaneamente para realizar o registro (Ponto de Cultura Quilombo do Sopapo, 2017). 
As câmeras estenopeicas ou pinhole são dispositivos que permitem a realização de fotografias sem a utilização de lente. As oficinas contaram com dois tipos delas, a saber: a câmera de caixa de fósforo e a de tubo de filme fotográfico 35 milímetros.

A primeira constitui-se de uma caixa de fósforo, pintada de preto por dentro e vedada com fita isolante. No lado maior é feita uma abertura na qual é colado um pedaço de papelalumínio, no qual é feito um pequeno orifício com a ponta de uma agulha. Em cima desse furinho é colada uma fita adesiva que pode ser removida para possibilitar a abertura e fechamento do furo, visando ao controle da entrada de luz dentro da caixa. No lado oposto ao que contém o furo, é colocado um material sensível à luz (no caso dessas oficinas, adaptou-se um rolo de filme fotográfico, no qual foram gravadas as imagens captadas). Quando o pequeno orifício é destapado, a luz penetra por um tempo, que é definido pelas condições de iluminação do ambiente, e a gravação da imagem é realizada. O tipo de filme utilizado foi o $35 \mathrm{~mm}$ colorido de ISO 100 (idêntico aos que eram utilizados nas câmeras fotográficas analógicas). Cada filme pode dar uma autonomia de 10 a 30 fotogramas ("poses"), aproximadamente, dependendo do tamanho do filme que é utilizado (Seidl, 2010). Os filmes das caixas de fósforo são revelados em um laboratório fotográfico comercial.

O material utilizado na câmera de tubo de filme fotográfico preto $(35 \mathrm{~mm})$ não permite a entrada de luz. É feito um furo na parte mais longa do tubo e segue-se um procedimento similar ao utilizado na caixa de fósforo, vedando-se o furo com papel-alumínio, no qual é feito um pequeno orifício com uma agulha, tapado com fita adesiva para possibilitar o controle da entrada de luz. Internamente, no lado oposto ao furo, o material sensível à luz utilizado foi chapa de raios $\mathrm{X}$ odontológico vencida, que não tenha sido utilizada, na qual as imagens captadas foram gravadas. Com esse material, as imagens produzidas são em preto e branco. Cada câmera desse tipo comporta apenas uma chapa de raios $\mathrm{X}$, que precisa ser substituída a cada foto, num ambiente protegido do contato com a luz. Em cada percurso fotográfico, os participantes das oficinas receberam quatro câmeras para a realização de quatro fotografias. As chapas de raios $\mathrm{X}$ podem ser reveladas pelos próprios participantes. Nesse caso, foi montado um laboratório no local da oficina (Ponto de Cultura Quilombo do Sopapo, 2017).

\section{Atividades pedagógicas da Oficina Sensibilização do Olhar: uso dos artefatos fotográficos}

Retratamos a seguir algumas das atividades pedagógicas desenvolvidas em cada localidade, como parte das oficinas, e compartilhamos interpretações sobre o potencial delas, no âmbito da Educação Permanente em Saúde.

\section{Atividade pedagógica 1 - Olhos vendados! A experiência de não enxergar}

Objetivo: sensibilizar o grupo para o uso dos artefatos a partir da subtração do sentido da visão.

Atividade: conversar com os olhos vendados. 
Após uma breve conversa sobre os objetivos da oficina, todos se sentavam em roda e, vendados com ataduras, respondiam às perguntas disparadoras da conversa: Eu sou...? O que me move? Qual é meu "perrengue”/desafio? Em todos os grupos, houve ainda uma quarta questão, que foi formulada coletivamente entre a equipe de facilitação da oficina e a coordenação dos projetos. Essa pergunta procurou trazer à tona uma dimensão singular que fosse significativa para os participantes: Como en experimento o sensivel neste curso de medicina? (agreste); Como en me vejo na Rede Cegonha? (planalto meridional catarinense); e Como minha prática ajudar a reduzir os casos de malária? (margens do Rio Juruá, Floresta Amazônica). Após todos responderem às perguntas, as ataduras eram retiradas e acontecia uma roda de conversa sobre os sentimentos vivenciados com a experiência.

\section{Análise da vivência}

Os participantes das oficinas vivenciaram um estranhamento na ação de falar com os olhos vendados. A experiência de estar de olhos fechados diante de seus companheiros de trabalho foi inusitada. Vivenciar o espaço coletivo, sem o recurso do olhar, produziu muitas reflexões sobre a valorização da escuta do outro e da escuta de si mesmo, ao passo que fez emergir novas sensibilidades sobre a função do olhar na produção de sentidos sobre o outro e a realidade. As novas perspectivas geradas seriam fundamentais para outras atividades previstas, envolvendo o fotografar com instrumentos rudimentares.

A escuta do outro e a escuta de si são elementos primordiais para incitar processos interativos necessários à produção da EPS e do mútuo desenvolvimento humano. Por meio da técnica, que demandou uma relação inusitada com o cotidiano, foi possível exercitar essas escutas e ativar a atenção de um modo diferenciado para si e para o outro, aguçando outros sentidos para potencializar a criação imagética. Alertou e integrou memórias, como o reconhecimento do colega por meio da voz; ativou a consciência do tempo que trabalham juntos, compartilhando em alguma medida suas trajetórias de vida, desafios e potências, tanto no âmbito pessoal como da relação com a instituição. Produziram autoanálise explicitando aspectos afetivos e socioemocionais envolvidos na prática profissional.

\section{Atividade pedagógica 2 - Silêncio e mãos à obra: confie nos seus olhos e no seu corpo!}

Objetivo: realizar uma tarefa de observação, utilizando o corpo como unidade de medida e sem utilização da fala.

Atividade: construção do pinholoscópio.

Cada participante foi convidado a construir, totalmente em silêncio, o seu pinholoscópio. A única fonte de informação era a observação dos gestos e movimentos dos facilitadores da oficina. Todos foram posicionados, lado a lado, ao redor de uma grande mesa, com acesso compartilhado aos materiais (papel cartão, vegetal e alumínio; cola, pincel e agulha), visualizaram e reproduziram, em um ritmo variado, seus próprios pinholoscópios. Para a construção do artefato, os únicos instrumentos de medida utilizados para o corte e a dobradura do papel foram as mãos e os dedos de cada participante, não sendo disponibilizadas régua ou 
tesoura. Terminada a construção do artefato, que levou entre 30 e 40 minutos, foi realizada uma roda de conversa sobre percepções e sentimentos vivenciados durante a experiência.

\section{Análise da vivência}

O exercício da observação exige aguçar a habilidade de interpretação, por parte do observador, de pistas visuais e sua transformação em gestos e movimentos que possibilitem a completa realização da tarefa. Durante a atividade, houve a preocupação dos facilitadores em promover uma coordenação coletiva do tempo de execução de cada etapa da tarefa, de modo que todos os participantes acompanhassem a demonstração e executassem as manobras concomitantemente, a fim de transformar os pedaços de papel em dois prismas que coubessem um dentro do outro. A observação dos companheiros de oficina, do próprio corpo, do ritmo coletivo do grupo; a necessidade de pedir ajuda, de ser solícito ao companheiro que demonstrava algum tipo de dificuldade ou carência de material promoveu a um só tempo desafios pessoais e coletivos.

Aqui é importante ressaltar que, em meio aos valores dominantes da educação no mundo ocidental, as habilidades manuais, em geral, deixam de ser cultivadas, na transição para a adultez, exceção feita aos artistas e artesãos. Essa tendência pode ter origem na influência das perspectivas pedagógicas e psicológicas tradicionais que desacreditam no desenvolvimento de habilidades e competências mentais e manuais, fora das janelas de desenvolvimento, associadas à infância e à adolescência. $\mathrm{Na}$ mesma linha, a tradição cartesiana da ciência faz do corpo uma dimensão secundária nos processos educacionais e na educação de adultos. Pressupõe-se que o adulto já se adaptou à habitual desconsideração do aspecto corporal nos processos de educação no trabalho. Com isso, perde-se a oportunidade de reencantar o corpo na produção de conhecimento.

Por essas razões, houve uma diversidade grande quanto à percepção de dificuldade da tarefa pelos participantes. Colar e dobrar, assim como brincar ou ficar em silêncio, faz parte das boas ou más memórias de infância. Muitos se surpreenderam, positivamente, com os resultados alcançados na construção do pinholoscópio, pois não acreditavam ser capazes de realizá-lo. Para os que tiveram mais dificuldade, a finalização da tarefa, com o uso prático do artefato, converteuse em fator de elevação da autoestima.

Outro ponto digno de nota nessa atividade, em que todos têm a mesma tarefa e produzem o mesmo artefato, mas cada um usando a sua própria medida corporal, é o fato de que não há duas mãos ou dedos idênticos, logo não houve dois pinholoscópios iguais. A utilização do corpo como unidade de medida, valendo-se das proporções singulares de cada um, possibilitou que os participantes refletissem sobre o tema da unidade na diversidade. Na primeira vez que a atividade foi realizada, no agreste, os facilitadores propuseram o exercício de subtração da fala, mas à medida que o grupo foi encontrando dificuldades para a realização da tarefa o silêncio foi rompido e, daí em diante, não se conseguiu atingir o objetivo de trabalhar apenas com base na observação do outro. No momento da avaliação da proposta, os participantes relataram que teria sido importante a equipe de facilitação sustentar com mais rigor a 
vivência dessa proposta, mesmo que a experiência trouxesse inicialmente ansiedade aos participantes. A equipe acolheu a avaliação e passou a sustentar a regra do silêncio nas demais localidades onde as oficinas ocorreram.

A adoção de formas menos comuns de comunicação, mediadas pela vivência do silêncio, e o aguçamento do sentido da visão e do tato, entre outros, promoveram diferentes formas de interação entre os membros do grupo e de cada um com o próprio corpo. Porém, para que essa experiência fosse vivenciada de forma pedagógica, ficou evidente que os facilitadores precisariam atuar com formas alternativas de comunicação e de apoio intencional aos participantes, a fim de que o desconforto inicial que a ausência de palavra trouxe a cada grupo não se convertessem em fonte de paralisia diante do inusitado. Dessa forma, a equipe se organizou para apoiar ativamente os participantes na realização da tarefa, mesmo sem usar a palavra.

\section{Atividade pedagógica 3 - Meu mundo de “pernas para o ar": recriando meu lugar}

Objetivo: experimentar um estranhamento na visualização e registro do cotidiano.

Atividade: percurso fotográfico

$\mathrm{Na}$ tela branca do papel vegetal presa em uma das extremidades do prisma interno que compõe o pinholoscópio, as imagens sempre aparecem de cabeça para baixo, visto que o pinholoscópio é a reprodução do interior de uma câmera, e a tela de papel vegetal permite ao observador ver como a imagem é formada dentro das câmeras. Houve, entre os participantes, um estranhamento inicial em face da descoberta de que, dentro do pinholoscópio, tudo aparecia de "pernas para o ar" e aquilo que estava à esquerda surgia à direita na tela de papel vegetal e viceversa.

A proposta de realização de percursos fotográficos envolvia que os participantes caminhassem pelo lugar e registrassem, com seus próprios celulares, os enquadramentos mais interessantes que conseguissem obter com $\mathrm{O}$ auxílio do pinholoscópio. Dessa forma, foi possível registrar o processo de (re)conhecimento do território onde atuam. $\mathrm{O}$ primeiro percurso fotográfico teve como produto diversos registros, os quais foram compartilhados com os demais participantes por meio da projeção das imagens digitais captadas pelos celulares.

\section{Análise da vivência}

A combinação de um artefato de visualização de imagens rudimentar, o pinholoscópio, com a câmera digital dos celulares, símbolo da contemporaneidade, provocou um diálogo entre diferentes gerações de tecnologias e suas respectivas possibilidades e limites. $O$ artefato rudimentar carrega uma estética e uma temporalidade "lenta", própria da representação pictórica, ou mesmo onírica, possibilitando a construção de uma narrativa cujo apelo estético é diferenciado da foto de uma câmera de celular.

A rusticidade do artefato convidou os participantes a soltarem a imaginação. A roda de conversa sobre as várias imagens produzidas e apresentadas trouxe à tona narrativas que subverteram a ideia de que a fotografia capta uma realidade dada e imutável. Muitas das imagens, quando registradas pela óptica do pinholoscópio, pareciam fotos antigas ou imagens de sonho, o 
que os fez resgatarem diferentes histórias, ativando memórias e projetos sobre o Lugar que os participantes compartilham cotidianamente, estranhando-o. Assim, a atividade mostrou-se potente para promover a imaginação e a memória que, sendo processos psicológicos superiores ligados ao funcionamento mental e aos processos de desenvolvimento humano no sentido mais amplo, podem potencializar práticas de Educação Permanente em Saúde.

Cabe destacar aqui que, na oficina realizada às margens do Rio Juruá, na Floresta Amazônica, um dos participantes produziu um novo artefato para acoplar ao pinholoscópio e facilitar a captação de imagens da tela branca, feita de papel vegetal, por meio do celular. Entre um dia e outro da oficina, os participantes levaram os pinholoscópios deles para casa. Um deles construiu um suporte para o seu celular com um pedaço de isopor recortado, de modo que ele ficasse firme para captação da foto. Esse suporteartefato contribuiu significativamente para a melhoria da qualidade das fotos obtidas. Esse é um exemplo da potência para a ativação da criatividade de um indivíduo ou grupo, mediada por atividades como as desenvolvidas na oficina.

Outra expressão significativa do uso do pinholoscópio ocorreu em seguida à oficina realizada no planalto meridional catarinense. As participantes compartilharam o conhecimento produzido na oficina com outros trabalhadores, envolveram outras equipes da rede. Elas mesmas promoveram uma oficina de construção de pinholoscópio, duas semanas após a vivência inicial, indicando que a proposta teve resultado positivo no que se refere à multiplicação do conhecimento e à produção de narrativas relacionadas ao fazer em saúde.

\section{Atividade pedagógica 4 - Luz? Câmera? Emoção! A construção das câmeras estenopeicas e o registro das ações cotidianas de educação na saúde}

Objetivo: criação de câmeras fotográficas rudimentares sem lente para registrar o cotidiano de trabalhos nos serviços de saúde e espaços de formação.

Atividade: construção da câmera fotográfica rudimentar e percurso fotográfico.

Assim como a construção do pinholoscópio, a confecção das câmeras rudimentares de caixa de fósforo foi realizada coletivamente, compartilhando-se os materiais. Já as câmeras de tubo de filme fotográfico não foram construídas com os participantes, apenas uma delas foi confeccionada pelos facilitadores, a título de exemplo, mas não houve tempo hábil, ao longo da oficina, para realizar a construção coletiva. Além do que, na Floresta Amazônica não havia um laboratório comercial para revelação de filmes fotográficos $35 \mathrm{~mm}$ colorido, optou-se pelo uso da câmera em tubo com filme de chapa de raios X. Esses participantes puderam vivenciar o processo de revelação das fotos no laboratório fotográfico, que foi montado para esse fim no próprio local da oficina.

Os percursos fotográficos foram realizados em Lugares que se relacionavam com a atuação profissional dos trabalhadores. Muitos conseguiram levar as câmeras para os próprios serviços/locais de trabalho cotidiano.

\section{Análise da vivência}

A presença dos artefatos gerou uma diversidade de reações entre os colegas de 
trabalho que não estavam participando da oficina, variando da desqualificação do artefato até a apropriação e ao compartilhamento do seu uso.

Um outro aspecto decorrente dessa oficina é que a construção de uma narrativa com o uso de câmeras fotográficas sem lente promoveu uma tensão entre a produção de intencionalidade do fotógrafo e a produção do inusitado. A revolução tecnológica da contemporaneidade, que permite a presença de câmera fotográfica digital nos diferentes equipamentos eletrônicos, promove um imediatismo na visualização da imagem produzida. Nas câmeras digitais, o resultado da foto é visualizado praticamente ao mesmo tempo em que ela é registrada e, se o resultado não é o esperado, apaga-se (deleta) e se toma outras imagens sucessivamente, até que o registro se adéque à expectativa do fotógrafo. A câmera rudimentar, de modo diverso, é analógica e exige outro tipo de relação com o tempo e com o resultado: a imagem só aparece depois da foto revelada e impressa, e inerente a ela está a surpresa em relação à possível distância entre a intencionalidade da ação do fotógrafo e o resultado da fotografia, que pode apresentar elementos inusitados.

A reação dos participantes às fotos reveladas provocou a ativação de processos afetivos e emocionais diante da sua prática, um exercício de abertura ao diferente. A permeabilidade ao novo permite ampliar o potencial de desenvolvimento pessoal e de identificação de processos de aprendizagem no trabalho, possibilitando que novos signos emerjam em relação às práticas de EPS.

O percurso fotográfico com as câmeras de caixa de fósforo e tubinhos preto de filme fotográfico foram norteadas pela proposta de que as imagens registradas se constituíssem em temas geradores para produção de narrativas sobre o local e as práticas cotidianas do trabalho em saúde de cada um dos projetos de EPS. Diferentemente do que foi o percurso fotográfico com o pinholoscópio, essa atividade propunha uma intencionalidade para orientar o olhar sensível dos participantes em direção à sua prática profissional. Parte dessas narrativas fotográficas foram utilizadas no livro, e o restante da produção do grupo foi materializada em fotos, impressas e produzidas para uma exposição fotográfica nos locais onde os projetos acontecem. Um dispositivo de sensibilização do olhar para as práticas de EPS e uma contribuição para comunicação de experiências relacionadas a dimensões do SUS que "dão certo" tanto no que alude ao atendimento aos usuários quanto na promoção de processos de desenvolvimento dos profissionais envolvidos.

\section{Considerações finais}

Apresentamos uma síntese das quatro atividades que compuseram a Oficina Sensibilização do Olhar e foram desenvolvidas em três localidades distintas, nas quais a fotografia funcionou como um dispositivo de promoção de desenvolvimento humano e EPS.

O processo de construção dos artefatos e os resultados alcançados em relação à produção de narrativas visuais sensibilizaram o olhar dos participantes, levando-os ao reconhecimento de trajetórias pessoais e coletivas de desenvolvimento humano. Da mesma forma, potencializaram processos de escuta e atenção, criatividade, abertura à alteridade e à novidade. 
Provocaram desnaturalizações sobre a realidade cotidiana do trabalho, permitindo a explicitação e o experimento de incertezas criativas, produzindo novos conhecimentos e EPS.

Assim, a produção de novos olhares para os processos de trabalho foi potencializada pela vivência do silêncio; utilização das medidas e proporções do próprio corpo; experimentação de outras temporalidades; utilização de insumos que fazem parte do contexto do setor saúde (como ataduras e chapas de raios $\mathrm{X}$ ); e pelo percurso na territorialidade no Lugar a que pertencem os trabalhadores. A utilização desses recursos também contribui com a construção da viabilidade financeira para a realização da atividade, visto que parte dos materiais já existem nos serviços de saúde e também podem possibilitar a ressignificação desses insumos.

O tempo escasso para realização das oficinas limitou a utilização de alguns dispositivos que poderiam ser mais explorados como potencializadores de EPS e desenvolvimento adulto. Porém a proposta destaca dois diferenciais que gostaríamos de ressaltar: o primeiro se refere à possibilidade de compor com a grandeza e a heterogeneidade socioeconômica, cultural e política do Brasil e ensejar uma prática alinhada com as potencialidades e necessidades do território como Lugar. O segundo é tratar-se de uma proposta de formação que promove a dimensão estética do trabalho e da própria existência, a partir da fotografia, como dispositivo de expressão artística singular. Ainda há dificuldade de reconhecimento da arte como dispositivo de produção de educação e desenvolvimento. Muitas vezes experiências como essas têm dificuldade de se consolidarem por falta de sensibilidade da gestão; entraves burocráticos para o setor saúde adquirir insumos artísticos; dificuldade de acesso a certos serviços e equipamento (o que ocorre em lugares longínquos do país, como a zona rural, as aldeias indígenas, a floresta, etc.). Apesar de diferentes experiências exitosas entre saúde, arte e educação em práticas de saúde mental, humanização e EPS, por exemplo, ainda é um desafio viabilizar o uso desse tipo de artefato como dispositivo para formação de trabalhadores da saúde. Desse modo, propõe-se que outros estudos sejam realizados no sentido de dar visibilidade ao potencial uso desses artefatos no desenvolvimento dos trabalhadores.

Por fim, o principal resultado alcançado com a experiência de EPS aqui relatada foi possibilitar que as criações fotográficas dos próprios trabalhadores compusessem o livro de projetos selecionados no InovaSUS 2015 Gestão da Educação na Saúde. Explicitando assim a importância da promoção de espaços de formação para trabalhadores do SUS que partam do reconhecimento de saberes Locais e possibilitem o estranhamento desse cotidiano e a construção de relações democráticas. Ações como essa se configuram como práticas de resistência para afirmação de espaços democráticos, pelo princípio da participação dos atores que compõe o SUS, mesmo num ambiente de adversidade institucional pelo qual o Brasil vem passando. Este é um produto das ações em EPS no SUS, cuja materialidade pode inspirar o fortalecimento da EPS no âmbito Local, sede da resistência onde se constrói possíveis caminhos para uma globalização solidária. 


\section{Referências}

Almeida, M. E., \& Valente, J. A. (2012). Integração currículo e tecnologias e a produção de narrativas digitais. Revista Currículo sem Fronteiras, 12(3), 57-82.

Anton, L. A. (2015). Cartografias faladas: memória viva do Lugar Cristal. Trabalho de conclusão de curso não publicado, Departamento de Geografia do Instituto de Geociências da Universidade do Rio Grande do Sul, Porto Alegre.

Bamberg, M. (1996). Narrative Development: Six Approaches. Mahwah, NJ: Lawrence Erlbaum Associates.

Bamberg, M. (2004). Form and Functions of "Slut-Bashing" in Male Identity Constructions in 15-Year-Olds. Human Development, 47(6), 331-353.

Baremblitt, G. F. (2002). Compêndio de análise institucional e outras correntes: teoria e prática (5a ed.). Belo Horizonte: Instituto Felix Guattari e Editora Record.

Ceccim, R. B. (2005). Educação Permanente em Saúde: desafio ambicioso e necessário. Interface - Comunicação, Saúde, Educação, 9(16), 161-168. Recuperado de https://dx.doi.org/10.1590/S141432832005000100013

Ceccim, R. B., \& Ferla, A. A. (2009). Verbete Educação Permanente em Saúde. In I. B. Pereira \& J. C. F. Lima (Orgs.). Dicionário da Educação Profissional em Saúde. Rio de Janeiro: Fundação Oswaldo Cruz. Escola Politécnica de Saúde Joaquim Venâncio. Recuperado de http://www.epsjv.fiocruz.br/dicionario/v erbetes/edupersau.html
Certeau, M. de. (1998). Artes de faz̧er: A invenção do cotidiano (3a ed.). Petrópolis: Ed. Vozes.

Lopes de Oliveira, M. C. S., \& Souza, C. Z. (2019). Work, Collaboration and Adult Development in a Digital Plataform for Permanent Education at the Brazilian Health Public System-SUS: A Cultural Semiotic Approach. In P. Bendassolli (Org.). Culture, Work and Psychology: Invitations to Dialogue (pp. 223-247). Charlotte: Information Age Publishing.

Lopes de Oliveira, M. C. S. (2012). Narrativas e desenvolvimento da identidade profissional de professores. Cad. Cedes: Campinas, 32(88), 369-378.

Lopes de Oliveira, M. C. S., \& Vieira, A. O. M. (2006). Narrativas sobre a privação de liberdade e o desenvolvimento do self adolescente. Educação \& Pesquisa, 32(1), 6782.

Luiz, I. C., Mello, A. da S., Ventorim, S., Ferreira Neto, A., \& Santos, W. dos. (2016). Investigação, Narrativa e Formação Continuada de Professores de Educação Física: Possibilidades para uma Prática Colaborativa. Journal of Physical Education, 27, e2721. Epub September 26, 2016.

Merhy, E. E. (2005). O desafio que a educação permanente tem em si: a Pedagogia da implicação. Interface - Comunicação, Saúde, Educação, 9(16), 172-174. Recuperado de https://dx.doi.org/10.1590/S141432832005000100015

Merhy, E. E. (2006). Salud la cartografía del trabajo vivo. Buenos Aires: Lugar Editorial.

Merhy, E. E. (2013). Educação Permanente em Movimento - uma politica de reconbecimento e cooperação, construindo encontros no cotidiano das 
práticas de saúde. Contribuição para o DEGES - SGTES - MS. Recuperado de http://eps.otics.org/material/entradaoutras-ofertas/artigos/ep-uma-politicade-reconhecimento-e-cooperacaoconstruindo-encontros-no-cotidiano-daspraticas-de-saude

Paleari, L. M. \& Biz, A. C. (2010). Imagens em narrativa: contraposição cultural e interdisciplinaridade no ensino fundamental. Ciência \& Educação (Bauru), 16(2), 491-506. Disponível em http://www.scielo.br/pdf/ciedu/v16n2/ v16n2a15.pdf

Ponto de Cultura Quilombo do Sopapo. (2017, 13 de junho). Projeto Imagens Faladas. Recuperado de https://projetoimagensfaladas.wordpress. com https://projetoimagensfaladas.wordpress. com/2011/11/10/buraco-de-agulha/

Portaria $n^{\circ}$ 1.996/GM/MS, de 20 de agosto de 2007. -(2007). Dispõe sobre as diretrizes para a implementação da Política Nacional de Educação Permanente em Saúde. Recuperado de http://bvsms.saude.gov.br/bvs/saudelegi s/gm/2007/prt1996_20_08_2007.html

Portaria n 198/GM/MS, de 13 de fevereiro de 2004. (2004). Institui a Política Nacional de Educação Permanente em Saúde como estratégia do Sistema Único de Saúde para a formação e o desenvolvimento de trabalhadores para o setor e dá outras providências. Brasília: MS.

Possamai, Z. R. (2007). Narrativas fotográficas sobre a cidade. Revista Brasileira de História,
27(53), 55-90. Recuperado de http://www.scielo.br/pdf/rbh/v27n53/a 04v5327.pdf

Relph, E. (2012). Reflexões sobre a emergência, aspectos e essência do Lugar. In E. Marandola Júnior (Org.). Qual o espaço do Lugar?: Geografia, Epistemologia, Fenomenologia ( pp. 17-32). São Paulo: Perspectiva .

Reznik, L., \& Araújo, M. da S. (2007). Imagens constituindo narrativas: fotografia, saúde coletiva e construção da memória na escrita da história local. História, Ciências, Saúde-Manguinhos, 14(3), 1013-1036. Recuperado de http://www.scielo.br/pdf/ciedu/v16n2/ v16n2a15.pdfhttp://www.scielo.br/pdf/c iedu/v16n2/v16n2a15.pdf

Rodrigues, A., \& Gonçalves, L. M. (2014). Narrativas digitais na formação de professores: da memória, do registro e do discurso emergem experiências. Revista Contexto \& Educação, 29(94), 212-237.

Santos, M. (2004). A natureza do espaço: técnica e tempo, raẓão e emoção (4a ed.). São Paulo: Editora da Universidade de São Paulo.

Seidl, E. (2010). Imagens faladas: uma reportagem fotográfica sobre a memória sobre o bairro Cristal. Porto Alegre: Ed. do Autor.

Sontag, S. (1981). Ensaios sobre a fotografia (2a ed.). Rio de Janeiro: Editora Arbor.

Sontag, S. (2004). Sobre fotografia. São Paulo: Companhia das Letras.

Recebido em: 05/08/2017 Aprovado em: 28/08/2018 